\title{
The multifactorial approach: children and adolescents Charalambos Sidiropoulos
}

\author{
Address: Open Psychotherapy Centre, Athens, Greece \\ from International Society on Brain and Behaviour: 3rd International Congress on Brain and Behaviour \\ Thessaloniki, Greece. 28 November - 2 December 2007 \\ Published: 17 April 2008 \\ Annals of General Psychiatry 2008, 7(SuppI I):S6 doi:I0.II86/1744-859X-7-SI-S6
}

This abstract is available from: http://www.annals-general-psychiatry.com/content/7/SI/S6

(C) 2008 Sidiropoulos; licensee BioMed Central Ltd.

The paper describes the therapeutic process in the case of a pre-adolescent with symptoms of functional primary encopresis, based on a multifactorial treatment for children and adolescents.

The specific therapeutic regiment includes participation both of the identified patient (child or adolescent) in group therapy activities (Multiple Activity or Psychodrama Group or Adolescent Group Analysis type), as well as and of the parental couple in a parents group on a monthly basis. It has been established that the above therapeutic regiment helps in developing the general aspect both of individual and family potential, which helps to utilize the healthy potential of the family system, to the advantage of both the 'patient' and the other family members.

The above therapeutic regiment appears to: 1) unify the family structure when split to the differentiated roles attributed first to healthy members (parents, siblings) and second to the unhealthy member (identified patient). 2) To mobilise the therapeutic potential in the family structure which in turn favours the persistence of the patient in his/her therapy, and 3) Enhances the benefits development and evolution both of the family structure as a whole and of each family member separately, especially of the identified patient who will gradually be relieved of the symptom which might not be mentioned at all during therapy. 